\title{
CONSULTA PREVIA Y TURISMO EN TERRITORIO DE COMUNIDADES AFRODESCENDIENTES: EL CASO DE LA ISLA DE BARÚ
}

Prior Consultation and Tourism in the Territory of Afro-Descendants Communities: the Case of the Barú Island

Martín Gabriel de la Rosa Rondón ${ }^{1}$

Fecha de Recepción: Noviembre 4 de 2013

Fecha de Aceptación: Noviembre 11 de 2013

SUMARIO: 1. Introducción; 2. La consulta previa; 2.1. La consulta previa en los instrumentos jurídicos internacionales y su desarrollo en el ámbito nacional; 2.2. Derecho de propiedad colectiva de los afrocolombianos; 3. La Isla de Barú y el megaproyecto turístico Playa Blanca Barú; 3.1. Componente histórico; 3.2. Componente socio-jurídico; 3.2.1. Los desalojos; 3.2.2. Los afrodescendientes; 3.2.3. La postura del gobierno; 3.3. Componente ambiental; 3.4. Análisis sobre la procedibilidad de la consulta previa; 4. Recomendaciones; 5. Conclusiones; 5. Referencias bibliográficas.

\footnotetext{
${ }^{1}$ Candidato a Doctor en Derecho, Universidad del Norte, Magíster en Derecho, Universidad del Norte, Especialista en Derecho Procesal Civil, formado por la Escuela Judicial "Rodrigo Lara Bonilla" en Restitución y Formalización de Tierras. Servidor de la Rama Judicial por más de 20 años, Juez Civil del Circuito Especializado en Restitución de Tierras de Cartagena.
} 


\section{COMO SE CITA ESTE ARTÍCULO (APA 6)}

De la Rosa Rondón, M. G. (2014) Consulta previa y turismo en territorio de comunidades Afrodescendientes: el caso de la Isla de Barú. (Y. Carrillo De la rosa, Ed.) Revista Jurídica Mario Alario D'Filippo, VI (11), pág. 94-121

\section{RESUMEN}

Este escrito analiza la difícil coexistencia, no siempre pacífica, entre el crecimiento económico y la preservación del patrimonio ambiental, histórico, social y cultural de las minorías étnicas enraizadas en Colombia, un país pluriétnico y multicultural. El documento explora y describe a partir de un estudio de caso, los mecanismos jurídicos nacionales e internacionales de defensa de los derechos de los afrodescendientes habitantes de la Isla de Barú, ubicada en el Distrito Cultural e Histórico de Cartagena de Indias, frente a la realización de megaproyectos turísticos público-privados que pueden producir efectos directos indeseables para su territorio.

\section{PALABRAS CLAVE}

Minorías étnicas, afrocolombianos, consulta previa, territorio, medio ambiente, Derecho.

\section{ABSTRACT}

This document analyzes the difficult coexistence, not always peaceful, between economic growth and environmental preservation, historical, social and cultural heritage of ethnic minorities rooted in Colombia, a multiethnic and multicultural country. The paper explores and describes from a case study, national and international legal mechanisms for defending the rights of Afro-descendants inhabitants of the Baru island, located in the Cultural and Historic District of Cartagena de Indias, facing the realization public-private tourism megaprojects that can produce undesirable direct effects on its territory.

\section{KEYWORDS}

Ethnic minorities, afrocolombians, consultation, territory, environment, law. 


\section{INTRODUCCIÓN}

Desde hace años, se viene impulsando la idea de desarrollar y explotar al país como destino turístico internacional, una industria sin chimeneas enfocada en el potencial geográfico y natural existente, de manera principal, en lugares de playa donde el entorno natural bien preservado se convierte en seductor negocio para los grandes grupos económicos. Uno de esos sitios es la Isla de Barú, ubicada en territorio del Distrito Cultural e Histórico de Cartagena de Indias, Capital del departamento de Bolívar. (Banco de la República, 2006)

La Isla de Barú ha sido escenario de proyectos turísticos varios, con complejos hoteleros y de descanso, y en la actualidad, se pretende ejecutar un nuevo megaproyecto denominado: Playa Blanca Barú, el cual ha reavivado la polémica sobre el ejercicio de los derechos de las minorías étnicas (en este caso afrodescendientes) que han ocupado de manera ancestral los terrenos que serán utilizados para el proyecto.

Este escrito pretende exponer el caso Playa Blanca Barú, examinando la aplicabilidad y eficacia del mecanismo contemplado en la Constitución Política de Colombia, el cual prescribe consulta previa como requisito ex-ante la realización de proyectos de intervención y explotación de recursos naturales y culturales en territorios de minorías étnicas.

El artículo se encamina a dar respuesta a interrogantes como: a). ¿Sería aplicable el requisito constitucional de consulta previa a los afrocolombianos que habitan la isla de Barú frente al megaproyecto turístico de Playa Blanca?, b).¿¿Es determinante el derecho de propiedad sobre el territorio donde se proyecta construir el megaproyecto para la procedencia de la consulta?; c). ¿En relación con el control ambiental y de protección de la biodiversidad, están legitimados los afrocolombianos que habitan la isla para intervenir?

Las anteriores son preguntas cuyas respuestas parecen obvias, sin embargo, ha sido tal la ambivalencia en la aplicación de los mecanismos de protección de los derechos de las minorías étnicas, que hoy es siempre necesario un análisis sobre casos particulares.

En esta situación existen además, otras circunstancias jurídicas y extrajurídicas que han llevado a que el trámite ni siquiera haya sido contemplado; ante la solicitud de algunos ciudadanos sobre el particular, las autoridades competentes han guardado hermético silencio.

Para cumplir con los propósitos señalados, este escrito ha sido dividido en dos partes: una primera general, agota los aspectos más relevantes sobre la consulta previa: a). concepto, b). concreción legal internacional y nacional, y, c). naturaleza del derecho de propiedad colectiva de afrodescendientes. Por otro lado, una segunda parte, más específica, se circunscribe a analizar las particularidades del macroproyecto turístico Playa Blanca Barú en varios aspectos: a. histórico, b. socio-jurídico, c. ambiental, y por último, d. un análisis particular sobre la procedibilidad de la consulta previa para el caso.

Para el desarrollo de los temas propuestos se acudió a la revisión de fuentes primarias, tales como 
registros, certificados, así como a fuentes secundarias especializadas sobre la materia (doctrina nacional e internacional), el contenido de la Constitución Política de Colombia y su desarrollo a partir de los fallos de la Corte Constitucional sobre el asunto.

\section{LA CONSULTA PREVIA}

La Consulta previa es un derecho fundamental de protección que tienen los pueblos indígenas y demás grupos étnicos, cuando se pretendan adoptar medidas (legislativas o administrativas) o cuando se vayan a realizar proyectos, obras o actividades dentro de sus territorios, buscando de esta manera salvaguardar su integridad social, cultural, económica y ambiental, así como garantizar su derecho a la participación.

El mecanismo busca defender a las personas, instituciones, bienes, trabajo, cultura y medio ambiente de estos pueblos, así como reconocer y proteger sus valores y prácticas sociales, culturales, religiosas, espirituales e institucionales. Según el Alto Comisionado de la Naciones Unidas (2008), "la consulta contribuye a la protección de los derechos de las comunidades afrocolombianas -negras, palenqueras y raizales-cuando entran en riesgo frente a las demandas y requerimientos de sociedades numéricamente mayoritarias y con mayor poder de decisión en las esferas de lo público y lo privado"2.

La institución, considerada parte del Derecho Internacional de los derechos humanos, ha sido tema constante de debate y análisis, especialmente en América Latina, donde existen más de 670 pueblos indígenas con una enorme y heterogénea demografía territorial y social, aplicable también a las poblaciones afrodescendientes (Popolo, Pinto, 2004). De acuerdo con la jurisprudencia de la Corte Constitucional Colombiana, y el apoyo del Artículo 1ㅇ del Convenio 169 de la Organización Internacional del Trabajo-OIT, sobre pueblos indígenas y tribales, se ha determinado que los afrocolombianos encajan como grupos tribales, y que por tanto, resultan cobijados por el derecho a la consulta.

El Convenio 169 de la OIT señala en su artículo 60 la obligación de: "consultar a los pueblos interesados, mediante procedimientos apropiados y en particular a través de sus instituciones representativas, cada vez que se prevean medidas legislativas o administrativas susceptibles de afectarles directamente".

En el mismo sentido, la Corte Constitucional de Colombia en Sentencia SU-039 de febrero de 1997 sobre la protección de los derechos fundamentales de las minorías étnicas señaló: "el derecho fundamental de la comunidad a preservar la integridad se garantiza y efectiviza a través del ejercicio de otro derecho que también tiene el carácter de fundamental, como es el derecho de participación de la comunidad". (Corte Constitucional de Colombia, Sentencia SU-039 de 1997)

Los fines cardinales del proceso de consulta, según la citada sentencia, se sintetizan en los

${ }^{2}$ Son las conclusiones del conversatorio institucional sobre consulta previa realizado por el alto comisionado de las Naciones Unidas para los Derechos Humanos en marzo de 2008. 
siguientes: a) Poner a la comunidad en conocimiento pleno de los proyectos que se realizarán en los territorios que ocupan, sus mecanismos, actividades y ejecución; b) Enterar a los tribales sobre la afectación de que pueden ser objeto por la ejecución del proyecto; c) darle oportunidad al grupo minoritario de valorar en forma libre y consciente las ventajas y desventajas del proyecto y ser oída en relación con las inquietudes que presenten en defensa de sus intereses; y, d) Escuchar el pronunciamiento de dicha comunidad tiene sobre la viabilidad del proyecto, garantizando su participación activa y efectiva en la toma de la decisión que deba adoptarse, la cual en la medida de lo posible debe ser acordada o concertada.

Como se ve, la consulta previa es un derecho fundamental que se convierte a su vez, en trámite obligatorio que debe ejecutarse de acuerdo con los usos y costumbres de cada etnia cuando se pretendan tomar decisiones que puedan afectarlos, las cuales pueden consistir en decisiones administrativas, como la expedición de una licencia ambiental para la explotación de recursos naturales, o legislativas, como la expedición de normas que involucren o afecten a estos pueblos. (Corte Constitucional Sentencia T-382 de 22 de mayo de 2006)

Sin embargo, los instrumentos jurídicos que regulan la consulta previa en Colombia, no conceden a las comunidades favorecidas el derecho de impedir la ejecución de la medida o proyecto, o en otras palabras, no las faculta para vetarlo, por el contrario, cuando no se produce la aceptación o consenso, el Estado tiene la potestad de establecer "los términos de la intervención, siempre que su determinación esté desprovista de arbitrariedad y autoritarismo, basada en criterios de razonabilidad, proporcionalidad y objetividad". Una limitación del mecanismo no establecida en los tratados internacionales ratificados por Colombia.

Teniendo en cuenta el vertiginoso crecimiento de las actividades económicas de empresas y conglomerados extranjeros, la mayoría con potencial de impactar las condiciones territoriales, ambientales y culturales de dichas comunidades, la postura de la Corte Constitucional ha venido siendo cada vez más prolija.

El punto de partida lo constituye la Sentencia T-769 de octubre de 2009, en la cual se señaló que en los casos de afectación intensa, las decisiones de las comunidades pueden llegar a considerarse vinculantes. Posteriormente, la Corte señaló en su sentencia T-129 de marzo de 2011 que, si la intervención o proyecto conlleva al aniquilamiento o desaparición de los grupos minoritarios, "prevalecerá la protección de los derechos de las comunidades étnicas bajo el principio de interpretación pro homine"; decisión que por supuesto, tuvo gran resistencia, hasta el punto de proponerse incidente de nulidad por supuesto cambio inconsulto de jurisprudencia, siendo desestimado por la Sala Plena en proveído del 12 de marzo de 2012 al tratarse de un desarrollo jurisprudencial y encontrarse ínsito en el Convenio 169 de la OIT. (Corte Constitucional de Colombia. Auto 053 de marzo 12 de 2012)

Por lo anterior, es que se puede afirmar que ante la ocurrencia de eventos como los anteriores, la consulta es una verdadera autorización previa a la ejecución de proyectos de este tipo. 


\subsection{LA CONSULTA PREVIA EN LOS INSTRUMENTOS JURÍDICOS INTERNACIONALES Y SU DESARROLLO EN ELÁMBITO NACIONAL}

En este título nos limitaremos a relacionar de manera no exhaustiva, los instrumentos jurídicos internacionales que se refieren a la consulta previa, para más adelante aludir a los que interesan de forma directa en objetivo del escrito.

En el orden internacional, se ha acogido al derecho a la consulta previa en varios ámbitos:

En el sistema de la Organización de las Naciones Unidas-ONU: el derecho a la consulta previa está presente en el trabajo de:

- Organización Internacional del Trabajo (OIT).

- Asamblea General de las Naciones Unidas.

- Comité de Derechos Humanos de las Naciones Unidas.

- Comité para la Eliminación de la Discriminación Racial (CEDR).

- Comité de Derechos Económicos, Sociales y Culturales (CDESC).

- Relatoría Especial de las Naciones Unidas sobre los Derechos Humanos y las Libertades Fundamentales de los Pueblos Indígenas.

- Foro Permanente de las Naciones Unidas para Cuestiones Indígenas.

En el Sistema de la Organización de los Estados Americanos-OEA y el Sistema Interamericano de Derechos Humanos-SIDH

- Asamblea General de la Organización de los Estados Americanos.

- Comisión Interamericana de Derechos Humanos.

- Corte Interamericana de Derechos Humanos.

\section{En el sistema de organismos financieros multilaterales}

- $\quad$ Banco Mundial.

- Banco Interamericano de Desarrollo (BID).

\section{En sistemas de responsabilidad empresarial}

- La International Petroleum Industry Environmental Conservation Association (Ipieca).

- La Comisión Mundial de Represas. (Rodríguez, 2010) 
Por su parte, en el plano del Derecho interno colombiano, las normas que regulan la consulta previa no están recogidas en un solo estatuto o código, por el contrario, se encuentran disgregadas en varias piezas del ordenamiento jurídico. Estas son:

- En la Constitución Política de 1991, Artículos 1, 2, 7,10, 13, 40,63, 68, 171, 246, 329, 330 y 356.

- En los Tratados y pactos internacionales que ingresan a nuestro ordenamiento mediante el Bloque de Constitucionalidad, por ser instrumentos internacionales de derechos humanos (Artículos 93 y 214 C. P.). Esencialmente el Convenio 169 de la OIT, aprobado internamente mediante la Ley 21 de 1991.

- En Leyes y Decretos, tales como: Ley 70 de 1993; Ley 99 de 1993 (Artículo 76); Ley 165 de 1994 (Artículo 14); Ley 300 de 1996; Decreto 1397 de 1996; Decreto 1320 de 1998; Ley 685 de 2001 (Capítulo XIV); Ley 200 de 2003 (modificada por el Decreto 4530 de 2008); Decreto 1745 de 2005; Ley 1101 de 2006; Resolución 3598 de 2008; Decreto 3770 de 2008; La Directiva Presidencial 01 de 2010; Resoluciones 0314 y 0315 de 2010 del Ministerio del Interior; Decreto 2820 de 2010 (artículo 15); Ley 1437 de 2011(Artículo 46); Decreto 4633 de 2011; Ley 1558 de 2012.

\subsection{DERECHO DE PROPIEDAD COLECTIVA DE LOS AFROCOLOMBIANOS}

Teniendo en cuenta que el asentamiento colectivo de minorías étnicas constituye un factor fundamental para el proceso de consulta previa, es necesario abordar lo relacionado con la propiedad de dichos grupos sobre las tierras donde se asientan.

El estado colombiano adoptó un criterio de "justicia social" en relación con la propiedad colectiva de indígenas y grupos étnicos sobre la tierra, lo anterior como consecuencia de la necesidad de compensar las inequidades y discriminación histórica a la que han sido sometidos, además del reconocimiento explícito de su realidad cultural, haciéndolos sujetos de especial protección.

Respecto de las comunidades afrodescendientes, la titulación colectiva de tierras se estableció partir en el Artículo Transitorio 55 de la Constitución Política de 1991, el cual señaló:

Dentro de los dos años siguientes a la entrada en vigencia de la presente Constitución, el Congreso expedirá, previo estudio por parte de una comisión especial que el Gobierno creará para tal efecto, una Ley que les reconozca a las comunidades negras que han venido ocupando tierras baldías en las zonas rurales ribereñas de los ríos de la Cuenca del Pacífico, de acuerdo con sus prácticas tradicionales de producción, el derecho a la propiedad colectiva sobre las áreas que habrá de demarcar la misma ley.

En la comisión especial de que trata el inciso anterior tendrán participación en cada caso representantes elegidos por las comunidades involucradas. La propiedad así reconocida solo será enajenable en los términos que señale la ley.

La misma ley establecerá mecanismos para la protección de la identidad cultural y los derechos de estas comunidades, y para el fomento de su desarrollo económico y social. 
Parágrafo 1. Lo dispuesto en el presente artículo podrá aplicarse a otras zonas del país que presenten similares condiciones, por el mismo procedimiento y previos estudio y concepto favorable de la comisión especial aquí prevista...

El desarrollo legal del mandato constitucional se dio con la expedición de la Ley 70 de agosto de 1993. Su objeto fue precisamente, reconocer a las comunidades negras que han venido ocupando tierras baldías en las zonas rurales ribereñas y establecer mecanismos para la protección de la identidad cultural y sus derechos como grupo étnico, así como el fomento de su desarrollo económico y social, con el fin de garantizar la obtención de las condiciones reales de igualdad de oportunidades frente al resto de la sociedad colombiana.

En otras Leyes, como la Ley 99 de diciembre de 1993, Ley marco ambiental de Colombia, se señaló en el Artículo 76, que la explotación de los recursos naturales deberá hacerse sin desmedro de la integridad cultural, social y económica de las comunidades indígenas y de las negras tradicionales, por lo que las decisiones sobre la materia se tomarán, previa consulta a los representantes de tales comunidades.

En la Ley 387 de julio de 1997, se adoptaron medidas para prevenir el desplazamiento forzado y establecer la atención, protección y estabilización de los desplazados, garantizando una protección especial para las comunidades indígenas y afrodescendientes. (Art. 10.8)

En la Ley 685 de 2001 (Código de Minas), se destacó el derecho preferente de las comunidades afrodescendientes para intervenir en las actividades mineras que se realicen o se puedan realizar en sus territorios. Según la Ley, la minería puede desarrollarse en los territorios de estas comunidades, siempre y cuando sus autoridades no ejerzan el derecho preferente a obtener el título minero (Artículo 35), siempre que se respete y proteja su identidad cultural (Artículo 130) y se les conceda los derechos sobre los yacimientos ubicados en sus territorios. (Artículo 131)

Es necesario hacer también referencia a la Ley 1152 de julio de 2007, la cual definió la política pública en materia de desarrollo rural, pues en ella se propuso beneficiar en los procesos de adjudicación de tierras, entre otros actores, a los miembros de las comunidades afrodescendientes minifundistas o que no posean tierras (Artículo 4). A pesar de lo anterior, como es conocido, dicha Ley fue declarada inexequible mediante Sentencia de la Corte Constitucional C-179 de marzo 18 de 2009, precisamente, por omisión del deber estatal de consulta previa a las comunidades indígenas y grupos étnicos que pudieran resultar afectados con sus disposiciones.

Por su parte, la afirmación de los derechos a la propiedad colectiva condujo a su vez, a la expedición de varios instrumentos reglamentarios, entre los más importantes destacan:

El Decreto 2663 de julio de 1994, a través del cual se reglamentaron algunos capítulos de la Ley 160 de 1994 (Sistema Nacional de Reforma Agraria), en el que se señaló que en los procedimientos de clarificación de la propiedad especiales, se deben legalizar también los territorios colectivos de las comunidades afrodescendientes. (Art. 18) 
El Decreto 1745 de octubre de 1995, por medio del cual se reglamentó la Ley 70 de 1993 en relación con el procedimiento para el reconocimiento del derecho a la propiedad colectiva de las tierras de comunidades negras y se fijaron los trámites específicos para la titulación de dichos territorios, instituyendo a los Consejos Comunitarios como máxima autoridad para su administración.

Por su parte, la ampliación de oportunidades para los afrocolombianos se expresa también en otras disposiciones como el Decreto 1627 de septiembre de 1996 por medio del cual, en cumplimiento de lo establecido por el Artículo 40 de la Ley 70 de 1993, se creó el fondo especial de créditos educativos para estudiantes de las comunidades afrodescendientes de escasos recursos económicos y buen desempeño académico, para facilitarles el acceso a la educación superior de pregrado y posgrado, así como a la formación técnica, tecnológica y en artes y oficios .

Ahora bien, como asunto concreto y específico a tener en cuenta en relación con la titulación de tierras a comunidades afrocolombianas, situación regulada esencialmente por la Ley 70 de 1993, es necesario destacar como desde el artículo $1^{\circ}$ de dicha Ley, se impone como requisito de procedibilidad que el territorio ocupado tenga la calidad de baldío en las zonas rurales.

Lo anterior se señala en este espacio, pues como avance de lo que será el estudio del caso concreto en la tercera parte del escrito, consideramos que la normativa especial analizada sobre propiedad colectiva a los grupos afrocolombianos resulta inaplicable a las tierras que integran la Isla de Barú, pues no reúnen dos de las condiciones requeridas, como son: ostentar la calidad de baldías y estar ubicadas en zonas rurales. El Instituto Colombiano de la Reforma Agraria-INCORA (hoy Incoder), mediante procedimiento administrativo, que en la época ocupó la atención de todo el País, dispuso mediante Resolución 134 de 22 de septiembre 1969: "declarar que no son baldíos los terrenos que integran la Isla denominada Barú, ubicada en jurisdicción Municipal de Cartagena, en el departamento de Bolívar".

Por otra parte, desde la expedición de la Ley 388 de 1997, los Planes de Ordenamiento TerritorialPOT del hoy Distrito Turístico y Cultural de Cartagena de Indias, han ubicado a la Isla de Barú como bien perteneciente al suelo urbano de la ciudad.

Sin embargo, como veremos adelante, a pesar de esta sui géneris condición, constitucional y legal, los afrocolombianos de Barú están facultados para controvertir la propiedad de los terrenos que han ocupado ancestralmente aún bajo los requisitos determinados en la Ley para la titulación ordinaria de bienes raíces, y además, son y deben ser sujetos de consulta.

\section{LA ISLA DE BARÚ Y EL MEGAPROYECTO TURÍSTICO PLAYA BLANCA BARÚ}

\subsection{COMPONENTE HISTÓRICO}

El sector de la Isla de Barú, hoy parte del Distrito Cultural e Histórico de Cartagena de Indias, fue poblado en su origen por los Indios Bahaire, quienes ofrecieron poca resistencia ante la llegada de los Conquistadores como Don Pedro de Heredia. Ya antes, en la Isla conocida como Tierrabomba, estos habían llegado a acuerdos con los indígenas de la étnia Carex. (DNP, 2006) 
Según los escritos de Mannix (1970), precisamente, atendiendo el carácter dócil de los indios de la zona, el Fraile dominico Bartolomé de las Casas aconsejó a los Reyes Católicos cambiar la mano de obra en el nuevo mundo, argumentando que la raza indígena era débil, y que por el contrario, la africana de mucha más resistencia para adelantar actividades de construcción de obras, redireccionando la esclavitud hacia África. De esa manera, alrededor de quince millones de esclavos Ilegaron al continente americano durante la época de la Colonia, al punto que Colombia es hoy, el tercer país de América en albergar personas negras de descendencia africana, después de Estados Unidos y Brasil. (Mosquera y Rodríguez, 2009)

Una de las grandes obras ejecutadas por la mano africana durante la Colonia, fue la construcción del denominado Canal del Dique, bifurcación artificial del Río Grande de la Magdalena construida en el siglo XVI para facilitar la navegación entre por el río hasta Cartagena. ${ }^{3}$ El canal cambió la topografía del terreno de Barú y la convirtió en Isla (a partir del 23 de octubre de 1649 que se culminó), dando inicio a los conflictos por la apropiación de la tierra, los cuales han subsistido hasta hoy.

Antiguamente, la Isla de Barú estaba compuesta por cinco grandes haciendas: Nuestra señora de la Concepción o Estancia Vieja, Hacienda Santa Ana, Hacienda Bajaire, Hacienda Cocón y Hacienda Porto Nao; su titulación se remonta a la época de la Colonia (1859), cuando el Cabildo de la Ciudad de Cartagena autorizó una Merced de Tierras ${ }^{4}$ en favor de particulares.

Según la Academia de Historia de Cartagena, en la época se realizaron varias Partidas sobre dichas haciendas: ${ }^{5}$

El 17 de septiembre de 1590 dos caballerías ${ }^{6}$ de la Isla de Barú a Merced de Don Luis de Esplugas; el 16 de noviembre de 1598 una Merced a Don Luis de Esplugas de cuatro

\footnotetext{
${ }^{3}$ El Canal del Dique tiene una longitud de 113 kilómetros, se desprende del Río Magdalena a la altura de Calamar y desemboca principalmente en la Bahía de Cartagena, aunque posee otras tres desembocaduras menores: Caño Correa (mar afuera), Caño Matunilla y Caño Lequerica. (hacia la Bahía de Barbacoas)

${ }^{4}$ Desde temprano, la Corona española organizó el acceso del colonizador a la propiedad de la tierra realenga: al respecto, las formas más comunes fueron las mercedes de tierras, la venta y la composición. La distribución de tierras por mercedes se efectuaba tanto al momento de fundarse una nueva población, como, más tarde, en la medida en que lo solicitan los interesados. Conquistadores, virreyes, gobernadores, audiencias y cabildos estuvieron, en uno o en otro momento del período hispánico, facultados para conceder mercedes en nombre del rey. En principio, el beneficiario de una merced podía ser cualquier vasallo español, indio o negro libre. Por lo general, la concesión de una merced de tierra implicaba algunas obligaciones para el beneficiario, que se orientaban básicamente a que la tierra no constituyera un factor de especulación sino de arraigo. La principal fue la de "vecindad", o sea la de residir en el lugar durante cierto lapso. Las Ordenanzas de población de 1573 mencionan, además, la construcción de edificios, el cultivo de las tierras y la crianza de ganado. Solo cumplidos los requisitos exigidos, el dominio queda perfeccionado y su titular puede disponer de la tierra como dueño para venderla, arrendarla, hipotecarla, legarla, etc. VIA INTERNET: http://www.banrepcultural.org/blaavirtual/revistas/credencial/mayo2002/propdetierras.htm. Fecha de Consulta 27/11/2012

${ }^{5}$ Parece oportuno advertir que las Partidas, enumeradas en último lugar entre las fuentes del derecho castellano vigentes en las Indias como derecho supletorio, alcanzaron de hecho un papel preponderante en la vida jurídica de estos territorios como código regulador de las instituciones de derecho privado. Via Internet: http://demo.dokeos.com/courses/UNAMCCH579f/document/Lecturas/BasesCapdequi.pdf?cidReq=UNAMCCHe650. Fecha de Consulta 27/11/2012.

${ }^{6}$ La palabra caballería está relacionada con la categoría del solicitante, porque originalmente eran tierras que se cedía a los caballeros como recompensa por sus actividades bélicas, aun cuando, en la práctica, una vez superada la fase de la conquista, se llegó a repartir a todo aquel que la solicitaba. Las caballerías tenían la forma de un paralelogramo, de ángulos rectos. VIA INTERNET: http://www.semarnat.gob.mx/temas/ordenamientoecologico/Documents/documento_volcan/basestecnicas/7_tenencia_tierra_me xico.pdf. Fecha de Consulta 27/11/2012
} 
caballerías de tierras en su estancia de Barú; el día 7 de diciembre de 1708 se remataron las Haciendas de campo que en la Isla de Barú tenía Don Diego de Quintana; el 26 de septiembre de 1849 Don Luis Manuela Ilana y Acueda Angulo y Pilar Madrid venden a Don Manuel González Brieva 7 caballerías; el 7 de junio de 1850 Don Manuel González Brieva vendió a Pilar Cortes, José Antonio Medrano, José Liberato Barrios, José Higinto Villalobos y Francisco Gómez 7 caballerías, quienes compraron en nombre y representación de la Parroquia de Barú; en los años de 1862 y 1863 los señores José Araujo y Pedro de Dávila mediante escrituras de 24 de octubre y 24 de julio vendieron a las señoras Margarita Macpherson de Bonoli y Juana Bonoli de Paz; en el año de 1872 mediante escritura No. 76 del 12 de julio, otorgada en la Notaría Primera de Cartagena, la señora Juana Bonoli de Paz vende a la Srta. Virginia Revollo la Hacienda de campo denominada: Santa Ana. En virtud de dicha tradición, todos los terrenos que conforman la Isla de Barú fueron declarados no baldíos y de propiedad privada, consecuentemente susceptibles de ser adquiridos y transferibles por acto inter vivos. (Incora, 1969)

Por su parte, un grupo de africanos, y más tarde sus descendientes, se establecieron en la Isla de Barú, y llegada la abolición de la esclavitud (1851), adquirieron parte de las tierras mediante compraventa, como fue el caso del negocio realizado con la Srta. Virginia Revollo, quien vendió a 94 comuneros la Hacienda Santa Ana de tres caballerías (aproximadamente 1.269 hectáreas) mediante Escritura Pública No. 129 de 12 de mayo de 1887, otorgada en la Notaría Primera de Cartagena, e inscrita en el Libro 1, Tomo 1, diligencia 161, de 13 de mayo de 1887.

Debido a una controversia con los propietarios de las fincas colindantes, en 1892 se tramitó un proceso especial de deslinde y amojonamiento, que culminó con una sentencia de 28 de abril de ese mismo año, dictada por el Juzgado Primero Civil del Circuito de Cartagena y confirmada por el Tribunal Superior; fallos que fueron protocolizados a través de escritura pública No. 355 de 29 de mayo de 1920 ante la Notaría Primera de Cartagena, inscrita en el Tomo 2, diligencia 689 de 8 de junio de 1920, página 180, de la Oficina de Registro de Instrumentos Públicos de Cartagena. Fungieron como compradores de dicha Hacienda, los señores: Aguedo Julio, Arturo Pacheco y otros 92 comuneros. (Superintendencia de Notariado y Registro, 2008)

\subsection{COMPONENTE SOCIO-JURÍDICO}

A mediados de los años sesenta (1965), un importante empresario colombiano comenzó a transmitir a otros hombres de negocios la idea de erigir a la Isla de Barú como paraíso turístico de descanso, bautizándolo como Playa Blanca Barú. (Revista Semana, publicación de octubre 24 de 1994)

Entre los años 1970 y 1993, los terrenos de la Isla fueron objeto de procesos de declaración de Pertenencia ${ }^{7}$, y mediante la figura de la prescripción adquisitiva de dominio, varias personas,

${ }^{7}$ El Código de Procedimiento Civil, para hacer efectivo el derecho sustancial del poseedor, en su Artículo 407 regló el denominado proceso de pertenencia, el que obviamente tiene por objeto la declaración de adquisición de dominio por el modo de la prescripción a favor de quien ha poseído por el tiempo y con los demás requisitos que exige la ley. Para el derecho, la prescripción puede entenderse como un instituto jurídico por el cual el transcurso del tiempo produce el efecto de consolidar las situaciones de hecho, permitiendo la 
naturales y jurídicas, miembros de familias interesadas en invertir en la zona, lograron títulos de propiedad sobre los lotes.

De los procesos civiles revisados para este escrito (20 en total), todos tuvieron como característica especial que estuvieron dirigidos contra persona indeterminada, esto es, de conformidad con el numeral 5o del Artículo 407 del Código de Procedimiento Civil, procesos que se promueven cuando no existen titulares de derechos reales inscritos ante las Oficinas de Registro de Instrumentos Públicos (de Cartagena en este caso). Lo cierto es que como se señaló atrás, toda la Isla de Barú tiene dueños (propietarios registrados desde la Colonia), por lo que no se entiende esta circunstancia.

A partir de 1980, algunos de los lotes adquiridos mediante los procesos de pertenencia señalados, entre los que se encuentra el $55 \%$ de las 438,8 hectáreas donde se proyecta construir el megaproyecto Playa Blanca Barú (usucapidas en su totalidad), fueron vendidos por los gestores del proyecto a la Corporación Nacional de Turismo-Corturismo, entidad que a su vez los traspasó al Ministerio de Comercio Industria y Turismo, y este finalmente, al Fondo Financiero de Proyectos de Desarrollo-Fonade. ${ }^{8}$

En 1994, bajo el gobierno del presidente Samper Pizano, se suscribió un acuerdo para desarrollar el proyecto turístico bajo la modalidad comercial de joint venture, pero desde mediados de junio de 1993 la firma estadounidense Wimberly Allison Tong \& Goo, especializada en este tipo de planificaciones, presentó el primer borrador de lo que podrían ser las instalaciones del mencionado complejo.

El convenio con dicha empresa se firmó el 24 de septiembre de 1994 entre los grupos económicos privados (con participación de un 45\%) y el ente Estatal (Corporación Nacional de Turismo, hoy Fondo Financiero de Proyectos de Desarrollo-Fonade con un 55\% de la participación). La inversión inicial calculada superaba los US\$500 millones de dólares y estaría compuesta por tres hoteles con 650 habitaciones, 500 villas, campo de golf de 18 hoyos, marinas, canchas de tenis, lagos, sitios de recreación, campos ecuestres, zonas comerciales y centro de convenciones.

Lo anterior se llevó a cabo bajo la intermediación del empresario Gabriel Echavarría Obregón y el extinto Ministerio de Desarrollo, con la justificación de una presunta necesidad de repeler las invasiones sobre varios lotes. La bendición para firmar el acuerdo la dio el gobierno SAMPER, con las herramientas jurídicas contractuales señaladas (Ibíd., Revista semana).

extinción de los derechos o la adquisición de las cosas ajenas. En el Derecho Anglosajón se le conoce como estatuto de limitaciones (statute of limitations). Cabanellas define dicha figura en los siguientes términos: "Prescripción: Consolidación de una situación jurídica por efecto del transcurso del tiempo: ya sea convirtiendo un hecho en derecho, como la posesión en propiedad; ya perpetuando una renuncia, abandono, desidia, inactividad o impotencia". Los hermanos Mazeaud señalan que la usucapión es la adquisición, por el poseedor de una cosa, del derecho de propiedad o de otro derecho real sobre esa cosa, por efecto de la posesión prolongada durante cierto plazo. VIAINTERNET:http://www.ejrlb.net/medios/docs/113/223_10_derecho_de_pertenencia.pdf. Fecha de Consulta $27 / 11 / 2011$

${ }^{8}$ Todos los certificados de tradición fueron revisados de manera personal. 


\subsubsection{Los desalojos}

Los herederos de los 94 afrodescendientes que adquirieron la Hacienda Santa Ana (mediante la escritura 129 de 1887), han alegado que el terreno donde se pretende desarrollar el megaproyecto turístico Playa Blanca Barú (438,8 hectáreas con 3,2 kilómetros de playa) hace parte de dicha Hacienda y que les pertenece, al igual que los predios donde se encuentran los corregimientos o poblados denominados Santa Ana y Ararca. El choque de intereses desde varias ópticas ha planteado la pregunta: ¿quién tiene mejor derecho sobre el mencionado terreno?, problemática que hasta la fecha no ha sido resuelta.

Desde 1995 comenzaron entonces, una serie de acciones judiciales y administrativas en contra de los afrodescendientes asentados en los predios destinados para el proyecto, tendientes a lograr el desalojo físico de las tierras habitadas ancestralmente. Ante la Fiscalía General de la Nación se presentaron denuncias por parte de los impulsores del proyecto invocando el presunto delito de invasión de tierras, lo cual produjo el libramiento de varias órdenes de captura; igualmente ante el Inspector de Policía del Corregimiento de Barú se presentaron querellas por la presunta perturbación de la posesión y ocupación de hecho, que en todos los casos culminaron con el desalojo de las familias Afrodescendientes. (Fiscalía Delegada ante la Corte Suprema de Justicia, Resolución de 20 de abril de 2006)

La situación desencadenó un conjunto de denuncias y demandas de parte y parte, (los inversionistas denunciaron a los afrodescendientes junto a sus apoderados, y estos a su vez, denunciaron a los inversionistas y sus apoderados). Como dato curioso se señala el caso de la nativa Amalia Imitola Julio, reseñada como la sindicada más vieja de Colombia, pues fue judicializada a la edad de 102 años y terminó su proceso con 104 años, su delito: ocupar la misma tierra en que nacieron y murieron sus ancestros. (Fiscalía General de la Nación, Resolución de 5 de septiembre de 2006)

En 2006 la Fiscalía General de la Nación decidió zanjar la cuestión acumulando las denuncias, las cuales pasaron a ser conocidas por un Fiscal Delegado ante la Corte Suprema de Justicia. El funcionario de la Fiscalía expidió una Resolución el día 20 de abril de 2006 en la cual precluyó la investigación en favor de todos los implicados de ambos bandos, y apelada la decisión se confirmó por el Vice-Fiscal General de la Nación a través de una Resolución de 5 de septiembre de 2006.

Las decisiones de la Fiscalía se fundamentaron en la existencia antiquísima de títulos en cabeza de los antecesores de los nativos, al igual que pruebas que acreditaban su posesión anterior a los títulos de los inversionistas privados, y también a que los dueños del Proyecto exhibieron títulos que los legitimaban para ejercer el dominio, concluyendo que la controversia debía ser sustanciada ante la jurisdicción Civil a través de un proceso ordinario que hiciera la confrontación de títulos y la delimitación física de la hacienda Santa Ana.

Sin embargo, como se dijo antes, no sucedió lo mismo con las acciones ante las autoridades administrativas, específicamente las querellas formuladas por los inversionistas privados y el Fonade ante el Inspector de Policía de Barú, quien despachó y ejecutó contra de los nativos el 
lanzamiento por presunta ocupación de hecho sobre los terrenos que integran el $100 \%$ del Megaproyecto Turístico (438,8 hectáreas). Teniendo en cuenta lo anterior, el Inspector dictó resoluciones y efectuó la desocupación, mediante varias decisiones y actuaciones, entre otras: Diligencia de 20 de septiembre de 2000, Resolución 0950 del 1 de agosto de 2002, Resolución 0149 del 5 de noviembre de 2005, Resolución 0111 del 17 de abril de 2006.

Desalojos, que al decir de los apoderados de los afectados y algunos medios de comunicación locales que registraron la información, ocasionaron el desarraigo de grupos de familias afrodescendientes de las tierras en que vivieron por varias generaciones, para pasar a engrosar la interminable cadena de desplazados en nuestro país, con todo el impacto social, cultural y político que semejante situación genera.

\subsubsection{Los afrodescendientes}

Los afrodescendientes de la Isla de Barú destacan por su capacidad para mantener las tradiciones, hábitos y costumbres. Existen similitudes entre las poblaciones con las actuales en el continente africano, por sus formas de vida, convivencia, comportamiento, etc. La vida diaria se hace en la calle, fuera de las cabañas, chozas o casas humildes; la sociabilidad se mantiene, tanto en mayores como en niños, los cuales se reúnen para jugar, pasear o hablar de sus cosas. (Información de fundacionespriu, 2012)

De acuerdo con Márquez (2009), las familias de los nativos, sus hogares y cosas se conciben como el legado de los primeros habitantes donde se concentraron miembros de la familia más allá del padre, madre e hijos, dándoles cabida a los nietos, sobrinos, hermanos y otros miembros; los hogares se conforman a temprana edad en la mayoría de los casos; la unión libre es el estado predominante. Para estas personas la familia se concibe como la unidad que le imprime valor a las nuevas generaciones, les trasmite todo el legado cultural y estabiliza la vida en comunidad porque es a través de la intervención de los miembros más adultos que se da solución a los distintos problemas. La educación es una forma estructurada de socializar donde el conocimiento, las actitudes y valores de una cultura se trasmiten formalmente de una generación a otra, la escuela es el marco de este proceso asume funciones básicas; primero en ella se enseña a leer y escribir, de igual modo donde se enseñan actitudes sociales como la autodisciplina y la obediencia a la autoridad.

En la Isla de Barú cada corregimiento celebra con gran fervor fiestas en honor a sus santos patronales, las que incluyen ceremonias religiosas y bailes populares:

Ararca celebra su fiesta el 3 de noviembre en honor a San Martín de Porras, Santa Ana lo hace el 26 de julio en honor a Santa Ana, y Barú, el 3 de mayo en honor a la Cruz de Mayo, estas fiestas tienen una duración de tres días o más de acuerdo con el presupuesto de los asistentes. En los tres corregimientos también se celebra de manera emotiva el 16 de julio, día de la Virgen del Carmen.

En los corregimientos de Ararca y Santa Ana es común observar a grupos de hombres departiendo en las esquinas y tomando licor todos los días, los fines de semana las mujeres se suman a estos 
grupos. En el corregimiento de Barú se aprecia este fenómeno los fines de semana. (Informe de la Alcaldía Distrital de Cartagena OTTB-128, 2010)

La comunidad que habita los terrenos de la antigua Hacienda Santa Ana, incluidos los corregimientos o poblados de Santa Ana y Ararca, se encuentra en extrema pobreza, condición que es el común denominador de los habitantes raizales de la zona, hasta el punto que hace unos años, el poblado de Ararca fue catalogado como el tercero más pobre del mundo. (Revista semana, Ibíd.).

Los habitantes (95\% afrodescendientes), se dedican esencialmente a la pesca artesanal y la elaboración manual de artesanías, es común entre la población que el trabajo no sea su actividad principal produciendo mermas en sus ingresos familiares. Los altos costos educativos no les permiten capacitarse, sobre todo en el campo del turismo, negocio en el que trabajan algunos habitantes de esta zona.

De acuerdo con Pizarro (2008), el 86\% de la población vive en casas construidas con ladrillos, madera y piedra pulida con pisos en cemento y gravilla, los cuales no cuentan con servicios públicos de acueducto y alcantarillado en un $98 \%$. Las principales fuentes de agua son la pila pública y el agua Iluvia; el hecho de carecer de alcantarillado hace que la mayoría de las familias no tengan servicio sanitario y que el $61 \%$ de la población use poza séptica cuyo mantenimiento es escaso. A todo lo anterior hay que agregar, que el $94 \%$ de las vías están en muy mal estado.

Para enfrentar dicha realidad y el abandono estatal, los afrodescendientes comenzaron a organizarse en asociaciones y comunidades que representasen sus intereses. Ejemplo de lo anterior, son las organizaciones Asobarú, Corconeisbarú, Consejo Comunitario de la Comunidad Negra del Corregimiento de Santa Ana, Consejo Comunitario de Comunidades Negras de la Comunidad Comunera del Gobierno Rural de Ararca; aunque algunos persistieron en hacerlo de forma individual, como es el caso de la nativa Lucía Alvarado Pacheco, heredera directa (nieta) del señor Arturo Pacheco uno de los 94 comuneros que fungieron como compradores de la Hacienda Santa Ana (a través de la escritura pública 129 de 1887).

Todas las anteriores organizaciones y personas tienen como objetivo principal los siguientes:

- Garantizar los derechos de los pueblos afrodescendientes de Cartagena;

- Preservar la integridad del territorio y su entorno cultural;

- Participar y decidir en todo lo que pueda afectar positiva o negativamente sus proyectos de vida;

- Que se tenga en cuenta el concepto de etnodesarrollo como referente incluyente de las comunidades y pueblos ancestrales; $y$,

- Defender la sostenibilidad ambiental de todos los proyectos que se ejecuten en la Isla.

En relación con la proliferación de los proyectos turísticos, los afrodescendientes reclaman a los 
inversionistas lo siguiente:

- Les sean respetados sus derechos de propiedad sobre los terrenos de la Isla,

- En su condición de propietarios que reclaman, le sean reivindicadas o restituidas las tierras de las cuales fueron desalojados,

- Como no se oponen totalmente al desarrollo turístico, de ser factible la ejecución de los proyectos, sean incluidos como copropietarios o partícipes de los mismos,

- En consecuencia, tengan responsabilidad social con la comunidad cuando plantean los megaproyectos,

- Se dé cumplimiento estricto a los acuerdos en que deben llegar con la comunidad Afro. (Resultados de la conferencia nacional de Organizaciones Afrodescendientes: mesa de dialogo Afrocartagenera 2011)

Ante las anteriores reivindicaciones, las organizaciones afrodescendientes han alcanzado algunos éxitos como resultado de su gestión, como fue impedir la construcción de un Puerto Carbonífero en la Isla, proyecto de la multinacional Coal Corp. S.A., la cual alcanzó a presentar solicitud para obtener licencia ambiental.

Teniendo en cuenta las condiciones socioeconómicas de las comunidades, desde ya los empresarios e inversionistas han iniciado la implementación de programas de salud, educación, vivienda, microempresas y subsidio social a través de:

- Donación de la clínica de Santa Ana,

- Instalación de puesto de salud en Barú,

- Construcción de un colegio con apoyo del Gobierno Nacional en Barú,

- Proyectar una Escuela de Formación Turística.

Igualmente, la Iglesia Católica a través del programa Minuto de Dios y en asocio con los inversionistas, han comenzado a impartir capacitación en oficios como la albañilería y mano de obra en construcción, lo cual le permitirá a los nativos adquirir conocimientos que puedan aplicar de iniciarse las obras de infraestructura del complejo turístico. (Revista semana, Ibíd.)

\subsubsection{La postura del Gobierno}

Hasta ahora el Gobierno ha estado abiertamente en favor del proyecto turístico, sin tomar mínimamente en consideración las reivindicaciones de los afrodescendientes.

A mediados de 2008, el entonces Vice-Ministro de Turismo, se pronunció en entrevista concedida a un diario de amplia circulación, en el sentido de que había sido resuelta la disputa sobre los terrenos 
de la zona turística, pues fueron erradicados los invasores, colocando a los impulsores del Proyecto en condiciones de comenzar su ejecución. Según lo manifestado en la entrevista, en 2010 debían iniciar los estudios, conceptos y permisos, comenzar a levantar la infraestructura en febrero de 2011 y la construcción del primer Hotel en 2012, terminando hacia mediados de 2020.

Por su parte, el Viceministerio de Comercio, el Consejo Nacional de Política Económica y SocialConpes y el Fonade, concordantes con los inversionistas privados, han señalado:

- Los afrodescendientes eran invasores y merecían el desalojo, pues ellos (los inversores) poseen títulos con una antigüedad cercana a los treinta (30) años.

- La ejecución del proyecto pondría a Colombia, y en especial a la Región Caribe, como destino turístico mundial del más alto nivel y gran competitividad.

- El proyecto generará 5.000 empleos directos y 20.000 empleos indirectos.

- Durante la construcción del mismo se generarán alrededor de 5.000 empleos.

- En su funcionamiento se generarán entre 3.000 y 3.500 empleos estables.

- Representará cambios de oportunidades económicas, de educación, de salud y en general de vida, para las poblaciones actuales y futuras. (Abrew, 2011)

Sin embargo, cuando todo apuntaba a la inminente iniciación del proyecto turístico, sus impulsores recibieron el más contundente y serio traspié, consistente la expedición del fallo de 2 de julio de 2008, proferido por la Sala Civil-Familia del Tribunal Superior de Cartagena, ya ejecutoriado, donde se le da prevalencia al título de una afrodescendiente, ordenando corregir la inscripción de la propiedad y restituirle 46 hectáreas más 6.440 metros cuadrados, ubicados en el centro del terreno en el que se planeó erigir el complejo turístico.

Este eslabón del conflicto lo inició de forma individual e independiente la nativa, heredera directa (nieta) del finado Arturo Pacheco, uno de los 94 comuneros que fungieron como compradores de la Hacienda Santa Ana (escritura pública 129 de 1887), quien previo el trámite de la Sucesión Intestada en la cual se adjudicó un lote denominado Los Pantanos que era la cuota parte de propiedad donde se asentó su antecesor y familia.

La señora Alvarado Pacheco presentó el día 19 de diciembre de 1996 demanda para proceso civil ordinario reivindicatorio contra la Corporación Nacional de Turismo y las empresas del Grupo Santo Domingo, que culminó con sentencia de primera instancia favorable a sus pretensiones fechada 8 de octubre de 2001 y proferida por el Juzgado Tercero Civil del Circuito de Cartagena; fallo que fue apelado por los demandados, pero confirmado por la Sala Civil-Familia del Tribunal Superior de Cartagena mediante sentencia del 2 de julio de 2008, dejándose trascurrir el término para interponer el recurso Extraordinario de Casación que procedía para ante la Sala de Casación Civil y Agraria de la Corte Suprema de Justicia, (omisión considerada como un monumental descuido de los apoderados de la parte demandada), quedando ejecutoriada y en firme la decisión. 
El fundamento de los fallos radica en que el estudio, análisis y confrontación de los títulos arrojó que es de mejor y más antigua procedencia el de la nativa frente a los títulos aducidos por los socios del proyecto, pues los de la primera datan de varias centurias y los invocados por los segundos son de pocos años a la presentación de la demanda reivindicatoria, además, estos se originaron en procesos de pertenencia dirigidos, como se señaló, contra personas indeterminadas, sin la citación obligatoria de los propietarios inscritos o sus sucesores (los 94 Afrodescendientes que compraron con escritura pública 129 de 1887), situación que hace a las declaraciones de pertenencia inoponibles a la demandante Alvarado Pacheco, pues según reiterada línea jurisprudencial de la Corte Suprema esos fallos de prescripción adquisitiva carecen de los efectos erga omnes que una providencia de esa naturaleza en condiciones normales produciría, debido a la violación de lo ordenado en el numeral 5ㅇ, Artículo 407 del Código de Procedimiento Civil .

El pronunciamiento de la jurisdicción civil originó la presentación de varias demandas civiles reivindicatorias, formuladas por los herederos de los 94 afrodescendientes que adquirieron la Hacienda Santa Ana en 1887, procurando también la restitución de los distintos lotes que conforman los terrenos donde se proyectó edificar el complejo turístico Playa Blanca Barú; avivando el conflicto.

Con el fundado temor de que los argumentos del fallo del Tribunal de Cartagena se convierta en jurisprudencia que guíe el sentido de las sentencias que deben dictar los Jueces Civiles del Circuito de Cartagena dentro de las nuevas demandas reivindicatorias, tanto Fonade, como las empresas del Grupo Santo Domingo y Echavarría, enfilaron armas para demostrar una presunta "corrupción" en la expedición de la sentencia de segunda instancia y su notificación. Para estos menesteres contrataron los servicios de un afamado profesional del derecho que presentó querellas disciplinarias y penales contra de los Magistrados (quienes dictaron el fallo) y la Secretaria General (quien lo notificó).

Actualmente la controversia continúa, reflejándose la problemática social que ello implica; las personas toman partido a favor de uno u otro bando, pero el interrogante aún no tiene respuesta final; mientras, al contrato inicial de participación se le hicieron "ajustes" para excluir del proyecto el lote reivindicado e integrar otro, incluyendo una redefinición donde los socios originales se convierten en puente para entregar la propiedad de los predios a un ejecutor de obras y promotor del proyecto que se encargue de su desarrollo y comercialización.

La decisión de la jurisdicción civil ha ocasionado otros fallos de la Corte Suprema de Justicia Sala de Casación Civil y Corte Constitucional, todos a favor de la nativa, acumulados en la sentencia T-211 de 27 de marzo de 2009.

\subsection{COMPONENTE AMBIENTAL}

Hoy día existe una creciente preocupación planetaria, pues la actividad humana está produciendo deterioros irreversibles en las condiciones del ambiente, la biodiversidad, y en general, en la salud y la calidad de vida de los seres humanos que habitan el planeta. 
A pesar de lo anterior, resulta paradójico que en Colombia, país considerado como megadiverso, y cuyo marco constitucional consagra un derecho constitucional de todos al disfrute de un medio ambiente sano (Art. 79), las zonas de gran diversidad natural sean objeto de la más evidente e impune degradación; basta con mirar la intensiva actividad minera desarrollada en los últimos años.

En el caso que se analiza en estas líneas hay un asunto de primer orden, y es precisamente, el relacionado con los aspectos ambientales del proyecto. Tal como señala la Política Nacional de Ecoturismo (2006), el tema turístico ha adquirido una connotación trascendental, en tanto que representa una actividad creciente, que involucra un mayor número de personas y que ha ido desarrollando una vocación pedagógica de especial importancia. En principios antagónicos, turismo y medio ambiente se han unido hoy y deben seguir uniendo esfuerzos, para conseguir objetivos comunes centrados en la conservación de los recursos naturales, en la generación de beneficios en la calidad de vida de las comunidades regionales y locales y en el logro de un objetivo de descanso y disfrute para los visitantes.

Con el Proyecto Playa Blanca Barú, se generarán sin duda fuertes impactos al ambiente que es necesario entender y prevenir o mitigar. De acuerdo con la literatura sobre evaluación de impactos ambientales, un proyecto de tales características puede producir efectos considerables desde el montaje hasta su desmantelamiento y abandono. Algunos de ellos son:

Las geoformas originales del terreno son modificadas por efectos de la remoción de árboles que facilita procesos erosivos; se presenta una pérdida del valor ecológico y ocasiona la migración de fauna terrestre y aérea hacia áreas boscosas vecinas o su extinción; se da una emisión intensiva de material particulado y gases a la atmósfera; se presenta un incremento en los niveles de ruido; es necesaria la eliminación de aguas servidas y desechos sólidos derivados de la operación del complejo (visitantes, empleados, etc.); se presentan cargas de sedimentos en todas las masas de agua,

Así mismo, se presentará un impacto en los cuerpos de agua por la actividad del buceo en los arrecifes; presión por el aumento de la demanda de servicios públicos como agua potable, alcantarillado, electricidad y telecomunicaciones que exigen mayor consumo de los recursos naturales; creación de barreras artificiales en la playas, entre otras; en fin, se alteran los ecosistemas originales. (Cepal, 2003)

Un país como el nuestro, con una biodiversidad compleja y riquísima, debe manejar de manera cuidadosa estos temas para no correr los riesgos que otros países diversos han sufrido. Es el caso de Huatulco (México), donde la Secretaría General de medio ambiente y recursos naturales de MéxicoSemarnat y la Procuraduría Federal de Protección del Ambiente-Profepa, clausuraron un hotel del Fondo Nacional del Turismo-Fonatur en 2009, ya que durante la etapa de construcción se abrió un camino para comunicar dos localidades desgajando un cerro del cual desapareció por completo la flora y fauna existentes. (Información aparecida en el periódico últimas noticias, edición No. 709 de 24 de febrero de 2009)

La Ley marco ambiental, Ley 99 de 1993, establece en su Artículo 47 la licencia ambiental, como 
requisito previo a la ejecución de obras, el establecimiento de industrias o el desarrollo de cualquier actividad, que de acuerdo con la ley y los reglamentos, pueda producir deterioro grave a los recursos naturales renovables o al medio ambiente o introducir modificaciones considerables 0 notorias al paisaje.

Desde su consagración en la citada Ley 99, la licencia ha sufrido casi diez modificaciones, la primera reglamentación se dio con el Decreto 1753 de agosto de 1994 y la última y vigente modificación, se encuentra en el Decreto 2820 de agosto de 2010. Con su finalidad preventiva, la licencia busca eliminar, mitigar o reversar los efectos nocivos de una actividad sobre los recursos naturales y del ambiente, también constituye un límite a la libertad de empresa e iniciativa privada al exigir la sujeción al ordenamiento ambiental.

Trayendo todas las anteriores prescripciones normativas al contexto del Proyecto Playa Blanca Barú, no cabe duda que la licencia ambiental debe ser exigida. No está de más recordar que el complejo turístico contará con cinco hoteles con 2.000 habitaciones, unas 500 villas, campo de golf de 27 hoyos, marinas, canchas de tenis, lagos, sitios de recreación, campos ecuestres, zonas comerciales y hasta centro de convenciones.

A pesar de lo anterior, hasta la fecha no se han expedido licencias ambientales y/o urbanísticas, ni existen solicitudes para otorgarlas.

La Contraloría General de la Nación, en su respectivo informe de auditoría sobre el proyecto, evidenció que no se han adelantado los estudios técnicos y los planes y proyectos necesarios para el adecuado manejo de las aguas servidas y su disposición final, así como la definición de presupuesto y planes de manejo y conservación de flora y fauna presentes en la zona de influencia del proyecto, mediante acciones y recursos que mitiguen el impacto ambiental. (Contraloría General de la Nación, 2009)

Ya existen antecedentes nefastos en zonas de influencia de la isla de Barú, como es el caso de la construcción de un Club Náutico de propiedad de la sociedad Las Palmas (socia del proyecto Playa Blanca Barú) que en 2007 fue sancionada por la Unidad Administrativa Especial de Parques Nacionales Naturales-UAESPNN, debido a la construcción de obras no contempladas en el Plan de Manejo Ambiental, y que afectaron al Parque Natural Nacional Corales del Rosario y San Bernardo.

La anterior infracción le ocasionó a la citada Sociedad de las Palmas, una pírrica sanción consistente en una multa cercana a los cuarenta millones de pesos, lo que sin duda, no compensa el daño irreparable que se le ocasionó al ecosistema coralino. (Minambiente, 2010)

\subsection{ANÁLISIS SOBRE LA PROCEDIBILIDAD DE LA CONSULTA PREVIA}

Al igual que ha ocurrido con el trámite de licencia ambiental, en todas las intervenciones del Gobierno y de los socios privados del Proyecto Playa Blanca Barú, puede constatarse que dejan totalmente de lado lo relacionado con la obligación de adelantar la Consulta Previa a las comunidades que habitan ancestralmente la isla. 
Teniendo en cuenta que la obligación de consultar a las comunidades o grupo étnicos surgió esencialmente de la incorporación del Convenio 169 de la OIT, la reglamentación establecida en nuestro país a través del Decreto 1320 de 1998 no establece un procedimiento concreto, debiendo ajustarse a las condiciones del grupo étnico consultado, siguiendo los principios de flexibilidad, buena fe y finalidad, según lo señala el mismo Convenio.

Sin embargo, como se señaló al inicio de este escrito, resulta vinculante la consulta cuando con el proyecto de intervención se pueda producir una afectación directa relacionada con intromisión en las dinámicas ambientales, económicas, sociales y culturales propias de la comunidad receptora.

En la Isla de Barú, tanto su territorio como sus grupos sociales receptores, son especialmente vulnerables, pues la protección de sus manglares, playas y ecosistemas coralinos, al igual que su economía, vida social y costumbres afrocolombianas, difícilmente pueden llegar a ser compatibles con un turismo masivo y de gran escala como el que se proyecta adelantar.

En el caso concreto del megaproyecto, la procedibilidad de la consulta previa viene sustentada por los siguientes argumentos:

i. Los afrocolombianos de Barú son sujetos de consulta debido a que cumplen las exigencias de pueblo tribal, establecidas tanto en el artículo 1 ㅇ del Convenio 169 de la OIT, como en la Ley 70 de 1993. De acuerdo con la Corte Constitucional, la definición está dada atendiendo a dos elementos: "(i) un elemento objetivo, a saber, la existencia de rasgos culturales y sociales compartidos por los miembros del grupo, que les diferencien de los demás sectores sociales, y (ii) un elemento subjetivo, esto es, la existencia de una identidad grupal que lleve a los individuos a asumirse como miembros de la colectividad en cuestión". (Corte Constitucional de Colombia, Sentencia C-169 de 14 de febrero de 2001)

Específicamente, los elementos objetivos de identifican así:

- La descendencia histórica de pueblos esclavizados traídos de África, siendo capaces de mantener sus tradiciones, hábitos y costumbres.

- Ser un sector de la población no dominante en la configuración del Estado-Nación.

- Los elementos culturales y tradicionales que los distinguen de otros grupos sociales, como las familias de los nativos, los hogares y cosas se conciben como el legado de sus primeros habitantes donde se concentran miembros de la familia más allá del padre, madre e hijos, dándole cabida a los nietos, sobrinos, hermanos y otros; los hogares se conforman a temprana edad en la mayoría de los casos, la unión libre es el estado predominante, estas personas conciben la familia como la unidad que le imprime valores a las nuevas generaciones, les trasmite todo el legado cultural y estabiliza la vida en comunidad porque es a través de la intervención de los miembros más adultos que se da solución a los distintos problemas. 
Por su parte, los elementos subjetivos se identifican de la siguiente manera:

- La auto-identificación entendida como identidad;

- La identificación como distintos de otros sectores de la sociedad;

- La voluntad de preservar su cultura.

- Están organizados en consejos comunitarios y organizaciones de base

En definitiva, son todos los anteriores, factores antropológicos y etnoculturales que los identifican como comunidad beneficiaria de la consulta previa.

ii. El megaproyecto turístico Playa Blanca Barú hace hoy parte de la Política de Turismo del gobierno nacional. Ya en el plan sectorial de turismo 2003-2006 denominado: Turismo para un nuevo país, se incorporó la intervención del Fonade en el contrato de cuentas de participación firmado con el sector privado. El Documento Conpes Económico 3333 de enero de 2005, sobre los Lineamientos de política en materia turística-proyecto Playa Blanca Barú, solicita al Ministerio de Hacienda y Crédito Público expedir un Decreto mediante el cual se autorice a Fonade a constituir y/o participar en cualquier tipo de sociedad para fomentar, promover y ejecutar el proyecto.

En virtud de lo anterior, los responsables de la consulta previa son, por una parte, el Estado por su doble condición, como signatario del convenio 169 de la OIT y como parte activa del megaproyecto, y por otra, el sector privado de manera compartida, como socio impulsor del megaproyecto.

iii. El tipo de afectación generada por el proyecto es directa, y por lo tanto objeto de consulta, lo cual se refleja en los aspectos ambientales, económicos, sociales y culturales anotados líneas atrás. El impacto ambiental vendría dado por la pérdida de la biodiversidad de la zona, la alteración de ecosistema marinos y costeros, la deforestación del bosque tropical en 438,8 hectáreas donde se pretende ejecutar el proyecto, la migración de fauna terrestre y aérea hacia áreas boscosas vecinas o su extinción, emisión de polvo y gases a la atmósfera, incremento en los niveles de ruido, impacto en los cuerpos de agua por actividades del buceo en los arrecifes, contaminación de las aguas de baño a causa de vertimientos domésticos e industriales, concentraciones de contaminantes orgánicos, inorgánicos y microbiológicos derivados de la operación del complejo (visitantes, empleados, etc.), modificaciones notorias al paisaje, entre otras.

Lo anterior sería suficiente para aceptar la procedibilidad de la consulta previa, ya que de conformidad con el Artículo 47 de la Ley 99 de 1993 y el Artículo 3 del Decreto 1320 de 1998, el proyecto requiere una licencia ambiental, y para la misma se deben adelantar los respectivos estudios de impacto ambiental y socioeconómico, con la obligatoria participación de la comunidad receptora.

En relación con los aspectos económicos, los afrocolombianos de Barú ven en la pesca artesanal el modo de subsistir, sin embargo, se verán afectados por la contaminación y al impedimento que el propio proyecto genera, ya que para ingresar a las zonas de pesca existiría un bloqueo con la 
infraestructura ubicada. También el turismo informal que practican se limitaría o desplazaría, con la nueva sociedad como operador turístico, conllevando a los nativos a buscar otra actividad para subsistir.

En cuanto a los aspectos sociales y culturales, estudios indican que existe la posibilidad que se dé sustitución de los nativos de la isla por otras poblaciones o servidores turísticos o ejercicio de actividades ilegales como delincuencia, prostitución infantil etc. La fabricación de artesanías manuales y la agricultura de "pan coger" se verían perturbadas en la etapa de construcción y puesta en marcha del proyecto; las actividades tradicionales que se trasmiten de generación en generación como la fabricación de artesanías manuales que son las huellas dejadas por estas comunidades y que las identifican, se irían abandonando y abriendo paso a nuevas dinámicas que trae el turismo en masa, siendo la población joven a las que les puede resultar atractivo esta forma de subsistir debido a la incorporación de personal de la comunidad para la actividad turística industrial.

La afectación directa sobre los grupos étnicos que habitan el entorno geográfico del proyecto, sus secuelas sobre la comunidad, sus recursos y su cosmovisión, resultan notorios. No cabe duda que la ejecución del mencionado proyecto turístico alterará las relaciones de los habitantes, su ambiente y todos los aspectos relacionados con anterioridad, incidiendo en sus condiciones de vida; circunstancias que hacen imperativo y obligatorio realizar la consulta previa.

iv. Como ya se dijo, a pesar de que la normativa especial sobre propiedad colectiva a los grupos afrocolombianos resulta inaplicable a las tierras que integran la isla de Barú, pues no reúnen dos de las condiciones requeridas (ostentar la calidad de baldías y estar ubicadas en zonas rurales), lo anterior no es obstáculo para la procedibilidad de la consulta previa, porque en estos asuntos se aplica de manera preferente el alcance general del Convenio 169 de la OIT, en el que no constan tales requerimientos.

Este asunto fue resuelto ya mediante Sentencia de la Corte Constitucional T-745 de septiembre de 2010, con Ponencia del Magistrado Humberto Antonio Sierra Porto, en la cual la misma autoridad ambiental de la jurisdicción del Proyecto Playa Blanca Barú, la Corporación Autónoma Regional del Canal del Dique-Cardique, niega la realización de consulta previa frente a la construcción y mejoramiento de la vía transversal de Barú, lo que, en términos generales, engloba la realización de tareas orientadas a la construcción de la carretera principal, de una longitud aproximada de 31 kilómetros, así como las entradas a los puertos de los poblados de la Isla, Ararca, Santana y Barú, entre otras actividades accesorias.

El argumento esgrimido por la Corporación fue el de un aparente incumplimiento de la regulación contenida en el Decreto 1320 de 1998 en punto al incumplimiento de ciertos lineamientos para la viabilidad de la consulta, a saber: "a. identidad cultural, b. ocupación de tierras baldías en las zonas rurales ribereñas, c. prácticas tradicionales de producción, y $d$. derecho a la propiedad colectiva sobre las áreas que habrá de demarcar la misma ley, lo que hace que estas tierras sean adjudicables". De acuerdo con Cardique, los anteriores son los requerimientos para la exigibilidad de la consulta, lo cual pugna con el alcance y elementos que a la misma reconoce el Convenio 169 de la OIT e, incluso, el mencionado decreto de cuyo texto no emana tal afirmación". 
En la misma Sentencia, la Corte señala:

"Es notoria la huella plantada por la ejecución del proyecto en cuestión, lo cual adquiere mayor trascendencia en vista de que los habitantes de la región se dedican a actividades como la pesca, el turismo, la acuicultura y la agricultura. En efecto, la incidencia del proyecto no alcanza exclusivamente las dinámicas ambientales y socio-económicas, pues incluso el sentido cultural de este grupo poblacional, concepto visto como la urdimbre que articula las tramas de significación construidas por los humanos y manifiestas en sus expresiones sociales, se ve trastocado por el sentido y la proporción en que las consecuencias mismas alteran la relación existente entre los sujetos que le componen, su ambiente y los componentes que le integran".

"Así las cosas, el proyecto de que se trata no solo afecta directamente a las comunidades ubicadas en su zona de influencia debido a su disposición geográfica sino que, igualmente, sus secuelas recaen de forma particular sobre la comunidad, su nicho y los recursos que le constituyen, dado que los elementos que representan su cosmovisión son efectivamente y representativamente limitados por las consecuencias que resultan del proyecto. He ahi el advenimiento del criterio primario para la obligatoriedad de la consulta a las comunidades étnicamente minoritarias que se vean potencialmente afectadas por una medida legislativa o administrativa, como lo es la construcción de una carretera de tales características y magnitud en el espacio que material y culturalmente un grupo tiene como propio".

Así las cosas, la consulta previa a realizarse frente al megaproyecto turístico Playa Blanca Barú ha de ser con garantía reforzada, esto es, contar con el consentimiento libre, informado y expreso de la comunidad afrocolombiana que habita la isla ancestralmente.

\section{RECOMENDACIONES}

Después de casi veinte años de conflicto, las partes pleiteantes no han logrado una solución definitiva a sus diferencias siendo indispensable recurrir al auxilio de otras disciplinas que aborden temáticas varias como el aspecto social, étnico, cultural, ambiental, así como otros que confluyan en la problemática. Lo anterior requerirá, sin duda, una nueva investigación con un mayor alcance que esta preliminar y orientativa.

Con los elementos de información obtenidos hasta ahora, es posible anticipar un concepto preliminar en orden a resolver la problemática planteada, y de no ser acogido, recurrir al trámite de consulta previa invocando mediante Acción de Tutela, ese derecho fundamental. La recomendación sería en el siguiente sentido:

i) Se plantea una devolución completa de los terrenos a los afrodescendientes como propietarios originales, y de paso, abandonar la idea de construir el complejo turístico para preservar en su integridad el medio ambiente. A pesar de lo anterior, no se pueden dejar de lado dos realidades: a) Que los socios del proyecto poseen títulos de propiedad sobre el terreno y no cesarán su lucha hasta que termine el último proceso; b) Que los afrodescendientes, también con títulos de propiedad, no se oponen totalmente a la explotación turística de la isla, y que sus condiciones económicas son precarias. Frente a 
esta situación se plantean a su vez, las siguientes alternativas:

1ㅇ) Los afrocolombianos que habitan la isla de Barú y son descendientes de los 94 comuneros que en 1887 adquirieron la Hacienda Santa Ana, deben agruparse en una gran cooperativa o sociedad similar que los incluya a todos. Un porcentaje de propiedad del terreno y del proyecto debería transferirse al ente, haciéndolos participes de manera efectiva. Las partes involucradas deben ponerse de acuerdo en una mesa de diálogo, para sacar adelante y con beneficio común el proyecto turístico con participación de las comunidades.

2) Modificar el proyecto evitando las grandes construcciones para reducir el impacto ambiental, de manera tal que la ejecución y explotación se acojan a las estrategias de promoción del ecoturismo (Bonfil, 1995), sin olvidar las disposiciones de orden nacional e internacional de inclusión de la comunidad receptora en la realización material y económica del proyecto.

De esta manera, sería incluida y fácilmente practicable la consulta previa.

ii) De no llegar a acoger el acuerdo planteado, se sugiere a los afrocolombianos habitantes de la isla de Barú organizados en Consejos Comunitarios, ejercer una acción de tutela como medio idóneo para proteger sus derechos fundamentales de grupo étnico minoritario, especialmente el derecho a la consulta previa, tal como quedó sentado en el punto de la procedibilidad desarrollado en líneas anteriores, y lo tiene establecido como regla la Corte Constitucional.

\section{CONCLUSIONES}

La expansión de los proyectos turísticos a gran escala en los territorios de los países en vía de desarrollo es una realidad actual, lo cual no es ajeno a Colombia donde se perfilan varios, entre ellos en la isla de Barú el denominado "Playa Blanca Barú". El negativo e inmenso daño ambiental que la ejecución de esos complejos produce resulta innegable.

A nivel nacional e internacional las comunidades receptoras paulatinamente han sido dotadas de algunas herramientas jurídicas y técnicas que les permiten defender su entorno natural. En nuestro país uno de esos mecanismos, como pudimos analizar, es el proceso de Consulta Previa obligatoria que jurisprudencialmente fue elevado a derecho constitucional fundamental a favor de los grupos tribales e indígenas.

Pero como se vio en nuestra exposición, el solo ordenamiento jurídico resulta insuficiente, se queda corto para resolver definitivamente y en todos sus frentes la tamaña problemática que ocurre en Barú, requierese la concurrencia de otras disciplinas y saberes trabajando de manera conexa hacia una finalidad común.

En este apretado estudio trabajamos de manera conexa con los distintos componentes que las variables del conflicto exteriorizan, iniciando con la incidencia histórica pasando por lo social, étnico, jurídico y cultural, para luego establecer la obligatoriedad de la Consulta Previa en este caso, 
dejando al descubierto la violación del derecho al debido proceso en la titulación de los predios a favor de los inversionistas, y resaltamos el gran impacto ambiental del proyecto; finalizamos con unas sugerencias, en las que se destacan el respeto a la ecología e implementación del concepto etnodesarrollo.

\section{REFERENCIAS BILIOGRÁFICAS}

\section{Libros y artículos publicados en revistas científicas}

BONFIL, Guillermo. (1995) “El etnodesarrollo: sus premisas jurídicas, políticas y de organización”. Tomo 2. México INAH/INI

DEL POPOlO, F., GARCíA DE PINTO, E., RIBOtA, B., AZEVEdo, M. (2011) "Pueblos indígenas y afrodescendientes en América latina: dinámicas poblacionales diversas y desafíos comunes". Serie investigar N.12. ALAP Editor, Brasil.

DE ROUX, G. (2010) “Políticas públicas para el avance de la población afrocolombiana”. Revisión y análisis. Publicación del Proyecto Regional: Población afrodescendiente de América latina. PNUD. Colombia.

ICONTEC (2007). "Norma Técnica Sectorial Colombiana: destinos turísticos de playa requisitos de sostenibilidad". Norma NTSC 001-2

LONDOÑO TORO, B. (1998) “Nuevos Instrumentos de Participación Ambiental”. Edit. Consultoría Ambiental y Colectiva. Bogotá.

MANNIX, D. (1970) “A History of Atlantic Slave Trade”. Madrid. Alianza Editorial SA.

MOSQUeRA, R., RODRÍGUEZ. M., LEÓN, D. (2009) “Escenarios post- durban para pueblos y personas negras, afrocolombianas, raizales y palenqueras". Facultad de ciencias humanas. Universidad Nacional. Bogotá.

ORGANIZACIÓN MUNDIAL DEL TURISMO. (2004) "Desarrollo sostenible del turismo", Indicators of sustainable Develoment for Tourism Destinations - A Guidebook, Indicadores de desarrollo sostenible para destinos turísticos.

PIZARRO, Y., D. M. (2008) “Estudio Socioeconómico de la población de Santa Ana, Barú". Fundación Hernán Echavarría Olózaga.

RODRÍGUEZ, G. C., LAM, Y. (2011). “Etnorreparaciones; la justicia colectiva étnica y la reparación a pueblos indígenas y comunidades afrodescendientes en Colombia". De justicia. Reino de los países bajos.

RODRÍGUEZ, G. C., MORRIS, M., ORDUZ, S. N., BURITICÁ, P. (2010) “La consulta previa a pueblos indígenas”. Los estándares del Derecho Internacional. Colección jurídica Global Universidad de los Andes.

\section{Información aparecida en medios de comunicación}

ABREW, N. (2011) "Santo Domingo se mete en el negocio hotelero en Barú". Información aparecida en el Diario la República. Sesión Economía. Publicación del 15 de septiembre de 2011. 
PERIÓDICO EL UNIVERSAL DE CARTAGENA, jueves 30 de agosto de 2012.

PERIÓDICO ÚLTIMAS NOTICIAS, No 709, Año 4, Febrero 24 de 2009, ufdcimagenes.uflib.ufl.edu/uf/00/09/58/93/00037/(709).pdf.

RADIO CARACOL (2008) Emisión del mes de septiembre de 2008, programa la W.

REVISTA SEMANA (1994, octubre 24) "Playa brisa y mar".

\section{Informes y documentos}

ALCALDÍA MAYOR DE CARTAGENA (2010) “Informe de Contratación de la Alcaldía OTTB-128/2010”.

ALCALDÍA MAYOR DE CARTAGENA (2001) “Decreto 0977 del 20 de noviembre de 2001”.

ALTO COMISIONADO DE LA ORGANIZACIÓN DE LAS NACIONES UNIDAS PARA LOS DERECHOS HUMANOS. (2008) "El derecho de los pueblos indígenas a la consulta previa libre e informada". Conclusiones del conversatorio institucional sobre consulta previa realizado en marzo de 2008.

CONTRALORÍA GENERAL DE LA REPÚBLICA (2009) "Informe de auditoría gubernamental con enfoque integral, modalidad especial, proyecto Playa Blanca Barú".

CEPAL, ILPES, NACIONES UNIDAS. (2003) "Serie manuales, Guía conceptual y metodológica para el desarrollo y la planificación del sector turístico".

CONSEJO SUPERIOR DE LA JUDICATURA, SALA JURISDICCIONAL DISCIPLINARIA (2010) "Providencia de 26 de julio". (Rad. 11001010200020090316200)

AGUILERA, M.; BeRnAL, C.; QUINTERO, P. (2006) "Turismo y desarrollo en el Caribe Colombiano". Documentos de trabajo sobre economía regional turismo y desarrollo en el Caribe colombiano. No. 79. Banco de la República.

CORTE CONSTITUCIONAL DE COLOMBIA. Sentencia SU-039 de tres (3) de febrero de 1997. Magistrado Ponente: Antonio Barrera Carbonell.

CORTE CONSTITUCIONAL DE COLOMBIA. Sentencia C-169 de catorce (14) de febrero de 2001. Magistrado Ponente: Carlos Gaviria Díaz.

CORTE SUPREMA DE JUSTICIA, FISCALÍA DELEGADA. (2006) “Resolución del 20 de abril”.

DEPARTAMENTO NACIONAL DE PLANEACIÓN. (2006) “Los pueblos indígenas de Colombia en el umbral del nuevo milenio".

INSTITUTO COLOMBIANO DE LA REFORMA AGRARIA. (1969) “Resolución No. 134”.

FISCALÍA GENERAL DE LA NACIÓN, Despacho del Vicefiscal General. (2006) "Resolución de 5 de septiembre". 
CONFERENCIA NACIONAL DE ORGANIZACIONES AFROCOLOMBIANAS. (2011) "Mesa de diálogo Afrocartagenera 19 de enero".

MÁRQUEZ ESTRADA, J. (2009) "Islas del rosario ¿propiedad privada o Baldíos Nacionales?". Trabajo realizado en la Facultad de Derecho de la Fundación Tecnológica Antonio de Arévalo. Cartagena

ORGANIZACIÓN DE LAS NACIONES UNIDAS. (2011) “América latina y el Caribe: atlas de un ambiente en transformación". Programa de Naciones Unidas para el Medio Ambiente.

PRoCuRAduría General De la nACIÓN, Provincial de Cartagena. (2009) "Auto de 31 de marzo". (Rad.141-003239-08)

PRocuraduría General DE LA NACIÓN, Provincial de Cartagena. (2009) "Auto de 31 de marzo". (Rad.141-003239-08) 